\title{
Reproductive traits in captive and free-ranging males of the critically endangered Iberian lynx (Lynx pardinus)
}

\author{
Natalia Gañán ${ }^{1}$, Adrián Sestelo², J Julián Garde ${ }^{3}$, Fernando Martínez ${ }^{4}$, Astrid Vargas ${ }^{4}$, \\ Iñigo Sánchez ${ }^{5}$, María José Pérez-Aspa ${ }^{6}$, José Vicente López-Bao ${ }^{7}$, Francisco Palomares ${ }^{7}$, \\ Montserrat Gomendio ${ }^{1}$ and Eduardo R S Roldan ${ }^{1,8}$ \\ ${ }^{1}$ Reproductive Ecology and Biology Group, Museo Nacional de Ciencias Naturales (CSIC), 28006 Madrid, Spain, \\ ${ }^{2}$ Fundación Bioandina Argentina, C1425FCF Buenos Aires, Argentina, ${ }^{3}$ Instituto de Investigación en Recursos \\ Cinegéticos (CSIC-UCLM-JCCM), 02071 Albacete, Spain, ${ }^{4}$ Centro de Cría en Cautividad del Lince Ibérico \\ 'El Acebuche', Parque Nacional de Doñana, Matalascañas, 21760 Huelva, Spain, ${ }^{5}$ Zoobotánico Jerez, 11404 Jerez \\ de la Frontera, Spain, ${ }^{6}$ Centro de Cría en Cautividad del Lince Ibérico 'La Aliseda', 23213 Santa Elena, Spain, \\ ${ }^{7}$ Department of Conservation Biology, Estación Biológica de Doñana (CSIC), 41013 Seville, Spain and ${ }^{8}$ Royal \\ Veterinary College, NW1 OTU London, UK
}

Correspondence should be addressed to E R S Roldan at Reproductive Ecology and Biology Group, Museo Nacional de Ciencias Naturales (CSIC); Email: roldane@mncn.csic.es

\begin{abstract}
The Iberian lynx (Lynx pardinus) is the most endangered felid in the world. Adequate genetic management of in situ and ex situ populations, and linkage between both, require knowledge on male reproductive biology and factors influencing it. We examined the influence of age, free-ranging versus captive conditions and seasonality on phenotypic, endocrine and semen traits, and links between reproductive traits and male fertility. Males had relatively small testes, produced low sperm numbers, a low proportion of normal sperm, and a high proportion of motile sperm. Young (2-year-old) males had lower testosterone levels, fewer sperm, and a lower proportion of motile and normal sperm than $\geq 4$-year-old males. No major differences were found in semen traits before and after the mating season or between free-ranging and captive males, although the latter had better sperm motility. Males with larger relative testes weight and more sperm copulated more frequently, whereas males that produced more sperm with higher motility produced more cubs per female. In conclusion, small relative testes size and low sperm quality could indicate either low levels of sperm competition or high levels of inbreeding. Young males are probably subfertile; there is a slight trend for males in the captive breeding programme to have better semen quality than wild males, and males with higher sperm production are sexually more active and more fertile. These findings have major implications for decisions regarding which males should breed, provide samples for the genetic resource bank, or participate in programmes involving the use of assisted reproductive techniques.

Reproduction (2010) 139 275-285
\end{abstract}

\section{Introduction}

The Iberian lynx is regarded as the world's most endangered felid and the most threatened carnivore in Europe (Nowell \& Jackson 1996). The species is the only feline included in the category 'critically endangered' of the IUCN/SSC Red List (IUCN 2009). The Iberian lynx is endemic to the Iberian Peninsula and was once distributed throughout it (Blanco 1998, Rodríguez 2007), although at present the natural population has about 200 individuals (Guzmán López-Ocón et al. 2002) distributed in two reproductively isolated subpopulations (Johnson et al. 2004) that inhabit Southern Spain (Blanco 1998, Rodríguez \& Delibes 2003, Rodríguez 2007). Recently, evidence for the presence of Iberian lynx in central Spain has been presented (Alda et al. 2008). Anthropic factors are presumed to be a major cause of population decline (Rodriguez \& Delibes 2004).

For many years, conservation efforts have focused exclusively on the ecology and in situ conservation of the species (Valverde 1963, Delibes 1979, Palomares et al. 2001, 2005, Fernández et al. 2002). Recently, an ex situ conservation programme including captive breeding and a genome resource bank had been initiated with the aims of maintaining a genetic- and demographicallymanaged captive population and generating new free-ranging populations through reintroduction (Vargas et al. 2007, 2008, 2009). Conservation of the Iberian lynx using both in situ and ex situ approaches will benefit 
from the use of assisted reproductive technologies (Wildt 1990, Lasley et al. 1994, Pukazhenthi \& Wildt 2004, Roldan \& Garde 2004, Pope et al. 2006, Swanson 2006) that would allow gene flow between populations separated by space or time (Pukazhenthi et al. 2006a, Swanson et al. 2007, Roldan \& Gomendio 2009). In particular, the collection, evaluation and conservation of spermatozoa will require essential baseline knowledge of lynx reproduction (Wildt 1994, Wildt et al. 1995) for the development of sperm cryopreservation and artificial insemination, and for reproductive examinations of captive or free-ranging males before the beginning of the breeding season.

Little is known about Iberian lynx reproductive physiology. The breeding season takes place from December to February or March, with a peak in female receptivity (oestrus) in January. Births are concentrated in the last 2 weeks of March and the first days of April. Males do not usually sire cubs before they are 3 years old ( $\mathrm{F}$ Palomares, unpublished data). Individuals older than 10 years are unlikely to breed although there are some reports of older animals siring young (Blanco 1998). Reproductive traits can be affected by a variety of factors such as inbreeding, age and physical condition, as well as by environmental factors such as seasonality and living conditions (e.g. captive or free-ranging).

Genetic variability in Iberian lynx is low (Johnson et al. 2004, Godoy et al. 2009), probably as a consequence of high levels of inbreeding among current populations, and this may negatively affect reproductive traits. Evidence suggesting a potential link between inbreeding and reproductive characteristics has been reported in cheetah (Acinonyx jubatus; Wildt et al. 1983, 1987b, Roth et al. 1995), Florida panther (Puma concolor coryi; Barone et al. 1994) and lion (Panthera leo; Wildt et al. 1987a), and studies on other taxa have shown that there is a clear relationship between levels of inbreeding and semen quality at the individual level (reviewed in Roldan et al. 2006a). Age is known to influence the quality of semen parameters, with young animals showing suboptimal traits (e.g. cheetah; Crosier et al. 2007). Seasonal differences may relate to changes in photoperiod, temperature or availability of food resources. Among seasonal breeders, females are known to restrict their reproduction to a limited period of time, but less is known about changes in male reproductive potential throughout the year. Some male felids are markedly seasonal, such as Pallas's cat (Otocolobus manul; Swanson et al. 1996), snow leopard (Panthera uncia; Johnston et al. 1994), Arabian leopard (Panthera pardus nimr; Haas van Dorsser \& Strick 2005), Eurasian lynx (Lynx lynx; Jewgenow et al. 2006) and bobcat (Lynx rufus; Gañán et al. 2009a). In contrast, male felids living in the tropics do not have a marked breeding season: caracal (Caracal caracal; Bernard \& Stuart 1987), ocelot (Leopardus pardalis;
Morais et al. 2002), tigrina (Leopardus tigrina; Morais et al. 2002), margay (Leopardus wiedii; Morais et al. 2002), jaguar (Panthera onca; Morato et al. 2004) or clouded leopard (Neofelis nebulosa; Wildt et al. 1986). Since the Iberian lynx lives in Mediterranean zones, where seasonal changes are less marked than at higher latitudes, it is possible that males of this species continue to produce spermatozoa over a period of several months. Although comparisons between wild and captive populations have found no differences in semen quality in cheetah, Pallas's cat or black-footed cat (Felis nigripes; Wildt et al. 1983, 1987b, 1993, Swanson et al. 2007), some authors have found poorer sperm quality in captive populations (jaguars: Morato et al. 2001). These differences are most likely due to the conditions in which animals are kept in captivity (e.g. space available, quality of the diet), as well as the physical condition of animals in the wild populations. Finally, traits and functional capacity of spermatozoa may also vary depending on whether sperm cells were collected via electroejaculation or from epididymides of dead animals. In domestic cats there are few functional differences between ejaculated or epididymal spermatozoa (Luvoni 2006, Tebet et al. 2006) but little information exists for wild felids.

The aims of the present study on reproductive characteristics of Iberian lynx males were to 1) assess Iberian lynx semen traits, 2) examine the effect of age on semen quality, 3) compare sperm parameters between captive and free-ranging males, 4) explore possible relations between sperm traits, 5) compare male reproductive characteristics before and after the breeding season, 6) compare ejaculated and epididymal sperm traits, and 7) assess possible relations between semen traits and male fertility.

\section{Results}

\section{Phenotypic, endocrine and seminal traits in different age groups}

Iberian lynx males (Fig. 1A) reached maximum body size when they were over 3 years old. Maximum values for head length $(17.7 \pm 0.3 \mathrm{~cm})$, total length $(104.7$ $\pm 1.4 \mathrm{~cm})$, withers height $(46.7 \pm 0.6 \mathrm{~cm})$ and thoracic perimeter $(45.6 \pm 0.8 \mathrm{~cm})$ were attained in $\geq 4$-year-old males, although these values were not statistically different from those recorded in males that were $\leq 3$ years old.

In males electroejaculated at the end of November and beginning of December, just before the breeding season, significantly higher body weights $(P=0.04)$ were found in animals that were $\geq 4$ years old when compared to 2-year-old males; no significant differences were seen between 3 - and $\geq 4$-year-old males. Testes weights $(P<0.01)$ were significantly lower in 2-year-old males in comparison to the other two age groups. 

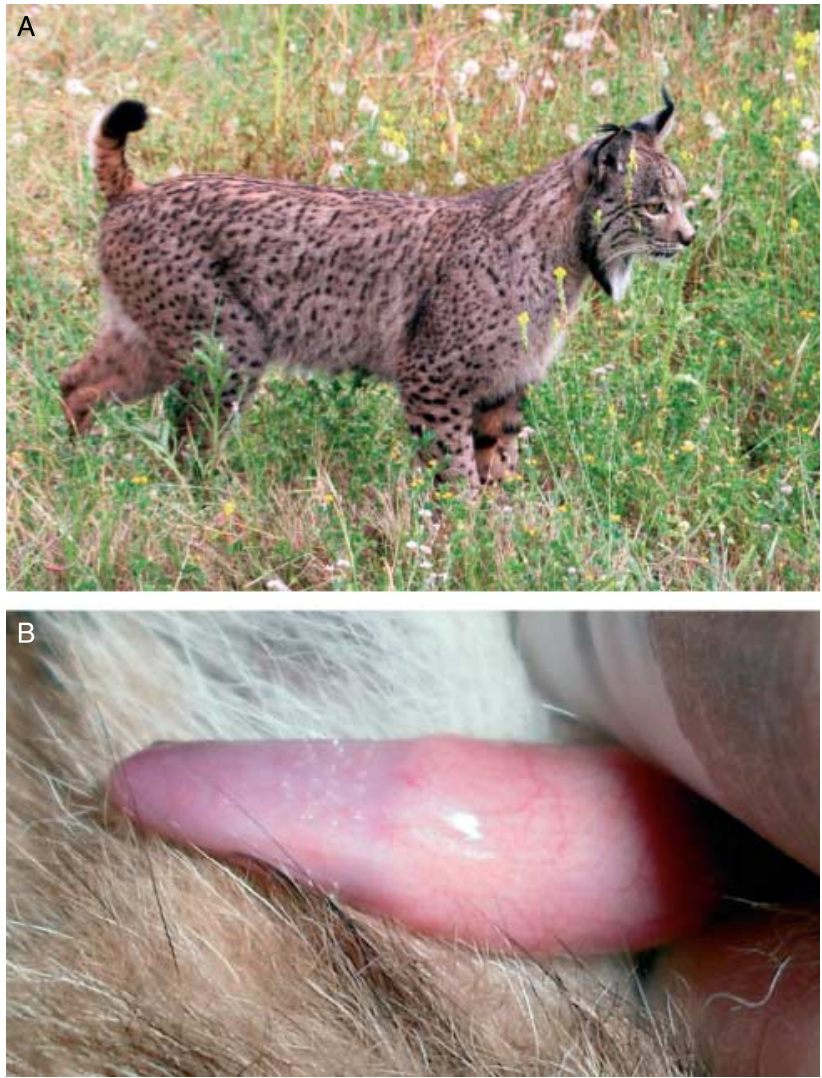

C

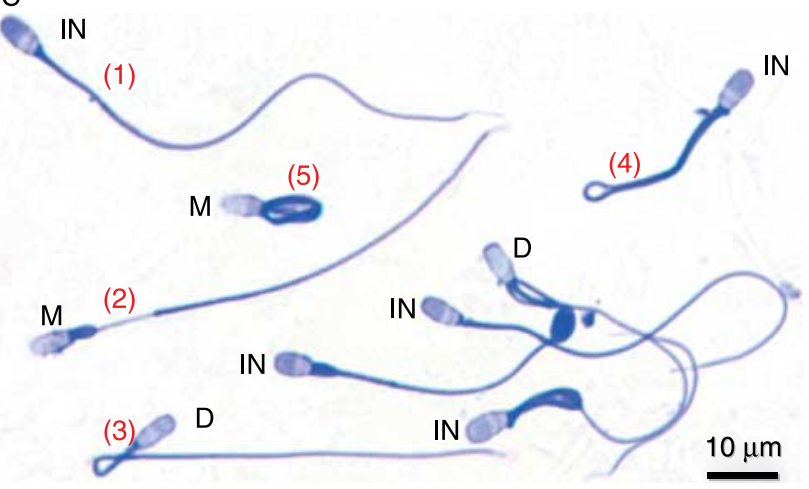

Figure 1 (A) Iberian lynx male from the captive breeding programme. (B) Penis of an Iberian lynx male; note the very small spines. (C) Iberian lynx spermatozoa stained with Coomassie brilliant blue and examined under bright field optics; morphology: 1) normal, 2) abnormal midpiece, 3) bent midpiece, 4) bent principal piece, 5) coiled flagellum; acrosome status: IN, intact, D, damaged, $M$, missing.

Despite these differences, relative testis weight was not different among the three age groups (Table 1). Circulating testosterone and cortisol levels were significantly higher in $\geq 4$-year-old in comparison to 2 -year-old males (Table 1). Testosterone levels in 3-yearold males were not different from the other two groups. The penis revealed the presence of small spines in the central area (Fig. 1B), but such spines were not present in all males.
Volume of the entire ejaculate and sperm concentration were lower in 2-year-old males (Table 1), although differences did not reach statistical significance. Total number of sperm in the ejaculate was significantly higher in $\geq 4$-year-old males than in 2-year-old animals; in 3-year-old males total sperm numbers were intermediate between those in younger or older males but were not significantly different from them. Significant differences were found between younger and older males in semen $\mathrm{pH}$, with younger males producing semen with $\mathrm{pH}$ 7.0, whereas older males' semen had a $\mathrm{pH} \sim 8.0$ (Table 1). Younger males (2 years old) produced semen with significantly lower motility (percentage of motile sperm and sperm motility index (SMI)) than $\geq 4$-year-old males. Finally, although 2 -year-old males had lower percentages of sperm with intact acrosomes than $\geq 4$-year-old males, differences were not statistically significant (Table 1). Two-year-old males had a larger proportion of abnormal sperm than $\geq 4$-yearold males, particularly in the principal and terminal piece (Fig. 1C, Table 2).

\section{Testicular, endocrine and seminal traits in captive and free-ranging animals}

There were no differences between males in different environments with the exception of a significantly lower percentage of motile spermatozoa in free-ranging males $(58.3 \pm 6.3 \%)$ than in captive ones $(77.8 \pm 4.9 \%$; $P=0.04$; Table 3). In agreement with this, two indices including motility (SMI and motility, quality and acrosome index (MQA)) were significantly lower in free-ranging males.

\section{Phenotypic, endocrine and seminal traits before and after the mating season}

Comparisons between ejaculates obtained from the same captive males in November-December (before the breeding season) and February-April (after the breeding season) revealed no significant difference (Table 4).

\section{Semen fractions}

Sperm traits of each of the four semen fractions collected during electroejaculation from all males older than 3 years were compared. Significant differences between series were found in the total number of spermatozoa, being higher in the first series $\left(4.1 \pm 1.5 \times 10^{6}\right.$ spermatozoa) than in the other three series of the electroejaculation $\left(1.0 \pm 0.3,0.5 \pm 0.1\right.$ and $0.3 \pm 0.2 \times 10^{6}$ spermatozoa in the second, third and fourth series respectively; $P=0.03$ in all cases; Fig. 2). In free-living $\geq 4$-year-old males, although the number of sperm was 
Table 1 Testicular, endocrine and semen traits of captive Iberian lynx males of three age groups just before the mating season.

\begin{tabular}{|c|c|c|c|c|}
\hline & \multicolumn{3}{|c|}{ Age of males } & \multirow[b]{2}{*}{ Kruskal-Wallis test } \\
\hline & 2 years $(N=4)$ & 3 years $(N=4)$ & $\geq 4$ years $(N=4)$ & \\
\hline Body weight (kg) & $9.7 \pm 0.46^{\mathrm{a}}$ & $11.3 \pm 0.69^{\mathrm{a}, \mathrm{b}}$ & $13.1 \pm 0.95^{\mathrm{b}}$ & * \\
\hline Total testes weight $(\mathrm{g})$ & $1.7 \pm 0.04^{\mathrm{a}}$ & $2.3 \pm 0.03^{\mathrm{b}}$ & $2.3 \pm 0.11^{\mathrm{b}}$ & * \\
\hline Relative testes weight $\left(\times 10^{-4}\right)$ & $1.7 \pm 0.08$ & $2.0 \pm 0.12$ & $1.7 \pm 0.08$ & NS \\
\hline Testosterone (ng/ml) & $0.30 \pm 0.14^{\mathrm{a}}$ & $0.59 \pm 0.19^{\mathrm{a}, \mathrm{b}}$ & $0.83 \pm 0.16^{\mathrm{b}}$ & NS $(P=0.15)$ \\
\hline Cortisol $(\mu \mathrm{g} / \mathrm{dl})$ & $9.0 \pm 1.86^{\mathrm{a}}$ & $17.7 \pm 3.47^{\mathrm{b}}$ & $20.0 \pm 4.57^{\mathrm{b}}$ & $*$ \\
\hline Ejaculate volume $(\mu \mathrm{l})$ & $279.7 \pm 56.03$ & $333.2 \pm 118.61$ & $333.5 \pm 32.43$ & NS \\
\hline Semen $\mathrm{pH}$ & $7.4 \pm 0.14^{\mathrm{a}}$ & $7.6 \pm 0.23^{\mathrm{a}, \mathrm{b}}$ & $8.0 \pm 0.03^{\mathrm{b}}$ & * \\
\hline Sperm concentration $\left(\times 10^{6} \mathrm{sperm} / \mathrm{ml}\right)$ & $6.6 \pm 4.44$ & $11.7 \pm 5.02$ & $29.5 \pm 10.79$ & NS \\
\hline Total sperm number $\left(\times 10^{6}\right)$ & $1.4 \pm 0.84^{\mathrm{a}}$ & $3.6 \pm 1.53^{\mathrm{a}, \mathrm{b}}$ & $9.1 \pm 2.68^{b}$ & * \\
\hline Motility (\%) & $70.1 \pm 3.85^{\mathrm{a}}$ & $83.2 \pm 3.33^{\mathrm{a}, \mathrm{b}}$ & $86.0 \pm 4.21^{\mathrm{b}}$ & NS $(P=0.07)$ \\
\hline Quality of motility (scale, $0-5$ ) & $2.7 \pm 0.25$ & $3.6 \pm 0.33$ & $3.2 \pm 0.19$ & NS \\
\hline Sperm motility index (SMI) & $62.6 \pm 4.25^{\mathrm{a}}$ & $77.3 \pm 3.89^{\mathrm{b}}$ & $74.8 \pm 3.70^{\mathrm{a}, \mathrm{b}}$ & NS $(P=0.08)$ \\
\hline Intact acrosome (\%) & $66.9 \pm 11.62$ & $66.8 \pm 7.21$ & $70.5 \pm 6.94$ & NS \\
\hline Motility, quality and acrosome index (MQA) & $65.3 \pm 7.20$ & $73.8 \pm 4.12$ & $73.4 \pm 2.33$ & NS \\
\hline
\end{tabular}

Relative testes weight $=$ total testes weight/body weight. Sperm motility index $(\mathrm{SMI})=(\%$ sperm motility $+(20 \times$ quality of motility $)) / 2$. Motility, quality and acrosome index $(\mathrm{MQA})=(\%$ sperm motility $+(20 \times$ quality of motility $)+\%$ intact acrosome $) / 3$. $*$ Significant differences $(P \leq 0.05)$ and NS, non significant differences after a Kruskal-Wallis one-way ANOVA by ranks. Comparisons between age groups were done using a Mann-Whitney test; between columns (age groups), different letters indicate significant differences $(P \leq 0.05)$.

slightly higher in the first fraction, no significant differences were found for this or for any of the other sperm traits (data not shown).

\section{Relation between ejaculate traits}

We examined possible relations between phenotypic and sperm traits in males that were $\geq 3$ years of age. There was a significant relation between serum testosterone levels and ejaculate volume $\left(r_{\mathrm{s}}=-0.51 ; P<0.05\right)$ and also between testes weight and ejaculate volume $\left(r_{\mathrm{s}}=0.56 ; \quad P<0.01\right)$. No associations were found between relative testes weight, or testosterone, and sperm parameters. There was a significant relationship between semen $\mathrm{pH}$ and the percentage of normal spermatozoa $\left(r_{\mathrm{s}}=0.52 ; P<0.05\right)$ as well as the percentage of intact acrosomes $\left(r_{\mathrm{s}}=0.42 ; P=0.05\right)$. No association was found between the total number of spermatozoa and the percentage of normal spermatozoa. A significant relation was observed between percentage of motile sperm and the quality of motility $\left(r_{\mathrm{s}}=0.66 ; P<0.01\right)$. In addition, the percentage of motile spermatozoa was significantly correlated with the percentage of intact acrosomes $\left(r_{\mathrm{s}}=0.46 ; P<0.05\right)$. Lastly, there was a significant correlation between the percentage of normal spermatozoa and the percentage of intact acrosomes $\left(r_{\mathrm{s}}=0.74 ; P<0.01\right)$ as well as the MQA index $\left(r_{\mathrm{s}}=0.55 ; P<0.01\right)$.

\section{Epididymal spermatozoa}

We attempted to recover spermatozoa post mortem from six males that died in the field. Testes and epididymides (usually one from each male) were recovered and examined between March 2005 and April 2008. Testes weight and sperm parameters were adjusted to account for values of both testes. Spermatozoa could be collected from four out of six males (Table 5). We observed considerable differences between males, mainly in the total number of spermatozoa (range: $0.5-31.1 \times 10^{6}$ spermatozoa) and in the proportion of normal sperm (range: $17-54 \%$; Table 5). Average values of epididymal sperm traits were similar to those observed in ejaculates from live free-ranging males

Table 2 Morphologically abnormal sperm of captive Iberian lynx males of various age groups, just before the mating season.

\begin{tabular}{|c|c|c|c|c|}
\hline & \multicolumn{3}{|c|}{ Age of males } & \multirow[b]{2}{*}{ Kruskal-Wallis test } \\
\hline & 2 years $(N=3)$ & 3 years $(N=4)$ & $\geq 4$ years $(N=4)$ & \\
\hline Morphologically abnormal sperm (\%) & $73.5 \pm 3.59^{\mathrm{a}}$ & $65.2 \pm 4.90^{\mathrm{a}, \mathrm{b}}$ & $56.2 \pm 4.20^{b}$ & NS $(P=0.1)$ \\
\hline Abnormal head $(\%)$ & $8.3 \pm 5.80$ & $4.6 \pm 3.21$ & $5.2 \pm 1.76$ & NS \\
\hline Dettached head (\%) & $3.1 \pm 0.73$ & $12.7 \pm 5.68$ & $7.6 \pm 2.66$ & NS \\
\hline Abnormal midpiece (\%) & $35.0 \pm 8.31$ & $28.3 \pm 3.69$ & $27.3 \pm 3.89$ & NS \\
\hline Abnormal principal and terminal piece $(\%)$ & $27.0 \pm 2.56^{\mathrm{a}}$ & $19.1 \pm 2.55^{\mathrm{a}, \mathrm{b}}$ & $15.2 \pm 1.06^{b}$ & * \\
\hline Sperm with cytoplasmatic droplet (\%) & $17.0 \pm 5.86$ & $10.9 \pm 2.91$ & $16.6 \pm 3.33$ & NS \\
\hline
\end{tabular}

*Significant differences $(P \leq 0.05)$; NS, non significant differences after a Kruskal-Wallis one-way ANOVA by ranks. Comparisons between age groups were done using a Mann-Whitney test; between columns (age groups), different letters indicate significant differences $(P \leq 0.05)$. 
Table 3 Testicular, endocrine and semen traits of free-ranging and captive Iberian lynx. Males were $\geq 3$ years old.

\begin{tabular}{lcc}
\hline & $\begin{array}{c}\text { Free-ranging } \\
(\mathrm{N}=4)\end{array}$ & $\begin{array}{c}\text { Captive } \\
(\mathrm{N}=9)\end{array}$ \\
\hline Age (years) & $7.0 \pm 1.78$ & $4.6 \pm 0.69$ \\
Body weight $(\mathrm{kg})$ & $14.3 \pm 0.80$ & $12.4 \pm 0.63$ \\
Total testes weight $(\mathrm{g})$ & $3.0 \pm 0.38^{\mathrm{a}}$ & $2.2 \pm 0.08^{\mathrm{b}}$ \\
Relative testes weight $\left(\times 10^{-4}\right)$ & $2.1 \pm 0.27$ & $1.8 \pm 0.12$ \\
Testosterone $(\mathrm{ng} / \mathrm{ml})$ & $1.17 \pm 0.40$ & $0.77 \pm 0.12$ \\
Cortisol $(\mu \mathrm{dg})$ & $10.8 \pm 0.82$ & $19.9 \pm 2.53$ \\
Ejaculate volume $(\mu \mathrm{l})$ & $470.2 \pm 83.36$ & $341.4 \pm 43.63$ \\
Semen $\mathrm{pH}$ & $7.4 \pm 0.26$ & $7.8 \pm 0.12$ \\
Sperm concentration & $10.1 \pm 4.06$ & $20.5 \pm 5.95$ \\
$\quad\left(\times 10^{6}\right.$ sperm/ml) & & \\
Total sperm $\left(\times 10^{6}\right)$ & $5.3 \pm 2.76$ & $6.8 \pm 1.58$ \\
Motility $(\%)$ & $58.3 \pm 6.30^{\mathrm{a}}$ & $85.6 \pm 2.25^{\mathrm{b}}$ \\
Quality of motility $($ scale, $0-5)$ & $2.7 \pm 0.32$ & $3.3 \pm 0.11$ \\
Sperm motility index $(\mathrm{SMI})$ & $55.8 \pm 5.83^{\mathrm{a}}$ & $75.7 \pm 2.04^{\mathrm{b}}$ \\
Morphologically normal sperm $(\%)$ & $25.9 \pm 5.95$ & $33.0 \pm 4.30$ \\
Intact acrosome $(\%)$ & $49.9 \pm 9.53$ & $68.8 \pm 4.42$ \\
Motility, quality and acrosome & $53.7 \pm 6.72^{\mathrm{a}}$ & $73.8 \pm 2.10^{\mathrm{b}}$ \\
$\quad$ index $($ MQA $)$ & & \\
\hline
\end{tabular}

Results are means \pm s.E.M. of samples collected in NovemberDecember, just before the mating season. Seminal traits are mean of whole ejaculate. Relative testes weight $=$ total testes weight/body weight. Sperm motility index $(\mathrm{SMI})=(\%$ sperm motility $+(20 \times$ quality of motility $) / 2$. Motility, quality and acrosome index $(\mathrm{MQA})=(\%$ sperm motility $+(20 \times$ quality of motility $)+\%$ intact acrosome $) / 3$. Comparisons between age groups were done using a Mann-Whitney test; between columns (age groups), different letters indicate significant differences $(P \leq 0.05)$.

from the Doñana population. There were differences in total testes weight and relative testes weight between free-ranging and captive males, with higher values in post mortem samples (compare values for free-ranging males in Table 3 with average values in Table 5). The sperm of two out of four males had no motility probably as a consequence of the period of time elapsed from the time these animals died until spermatozoa were recovered.

\section{Relations between semen traits and male fertility}

We analyzed breeding outcomes of captive males throughout 2006-2008 and compared these data with semen characteristics of the same males as assessed after electroejaculation about 1.5-2 months before the breeding season. Only mating of males and females that were $\geq 3$ years old were considered. In a given mating season, each reproductive male was housed with a single female at a time; some males were later paired with a different female in a separate enclosure.

There were significant correlations between males' relative testes weight and the average number of matings per female $\left(r_{\mathrm{s}}=0.65 ; P=0.02\right.$; not shown), as well as with the number of matings with the first female when a male was scheduled to mate twice $\left(r_{\mathrm{s}}=0.75 ; P=0.01\right.$; Fig. 3A). Moreover, a significant correlation was observed between the total number of spermatozoa in the ejaculate and the number of copulations with the first female with which he mated $\left(r_{\mathrm{s}}=0.63 ; P=0.03 ;\right.$ Fig. $\left.3 \mathrm{~B}\right)$. Semen traits were also related to the number of cubs delivered by females, as seen when comparing females that gave birth to two versus three cubs (Fig. 3C and D). Thus, a higher total number of spermatozoa in the ejaculate was significantly associated with a higher number of cubs (Mann-Whitney $U=2.00 ; P=0.05$; Fig. 3C). Furthermore, better sperm motility (as revealed by the SMI) in the ejaculate was observed in males that sired three cubs per female in comparison to males that sired two cubs per female (Mann-Whitney $U=0.00$; $P<0.05$; Fig. 3D).

\section{Discussion}

In the present study, we provide the first assessment of phenotypic, endocrine and semen traits of critically endangered captive and free-ranging Iberian lynx. The results have uncovered differences related to male's age, but no major difference between captive or free-ranging individuals, or between ejaculated and epididymal spermatozoa. Furthermore, we found co-variation between ejaculate traits and relationship between phenotypic and seminal traits and fertility of males in the captive breeding programme.

Testes weight in Iberian lynx and, consequently, relative testes weight are low when compared to other mammalian species (Kenagy \& Trombulak 1986, França \& Godinho 2003). Moreover, the absolute and relative testes weight of Iberian lynx are also low compared with other felid species with similar body mass such as the caracal (Bernard \& Stuart 1987), the fishing cat

Table 4 Phenotypic, testicular and semen traits of captive Iberian lynx males before and after the mating season.

\begin{tabular}{lcc}
\hline & $\begin{array}{c}\text { Before breeding } \\
\text { season }(N=3)\end{array}$ & $\begin{array}{c}\text { After breeding } \\
\text { season }(N=3)\end{array}$ \\
\hline Ejaculate volume $(\mu \mathrm{l})$ & $453.0 \pm 73.16$ & $660.7 \pm 178.23$ \\
Semen $\mathrm{pH}$ & $8.0 \pm 0.15$ & $7.7 \pm 0.21$ \\
$\begin{array}{c}\text { Sperm concentration } \\
\left(\times 10^{6} \text { sperm/ml) }\right.\end{array}$ & $8.1 \pm 3.86$ & $20.7 \pm 7.41$ \\
$\begin{array}{l}\text { Total sperm }\left(\times 10^{6}\right) \\
\text { Motility }(\%)\end{array}$ & $3.3 \pm 1.13$ & $15.2 \pm 6.76$ \\
$\begin{array}{l}\text { Quality of motility } \\
\quad \text { (scale, } 0-5)\end{array}$ & $76.7 \pm 6.71$ & $62.1 \pm 14.32$ \\
Sperm motility index $(\mathrm{SMl})$ & $3.1 \pm 0.11$ & $2.8 \pm 0.12$ \\
Morphologically normal & $69.1 \pm 4.35$ & $59.4 \pm 8.15$ \\
$\quad$ sperm $(\%)$ & $21.7 \pm 3.33$ & $20.1 \pm 1.84$ \\
Intact acrosome $(\%)$ & $40.1 \pm 3.50$ & $33.1 \pm 1.24$ \\
Motility, quality and & $59.5 \pm 2.75$ & $50.6 \pm 5.75$ \\
$\quad$ acrosome index $(\mathrm{MQA})$ & & \\
\hline
\end{tabular}

Results are mean \pm s.E.M. of samples from the same males collected in February-April and in November-December. Sperm motility index $(\mathrm{SMI})=(\%$ sperm motility $+(20 \times$ quality of motility $)) / 2$. Motility, quality and acrosome index $(\mathrm{MQA})=(\%$ sperm motility $+(20 \times$ quality of motility) $+\%$ intact acrosome) $/ 3$. Comparisons between groups were done using a Wilcoxon's test for paired samples; there were no statistical differences between groups. 

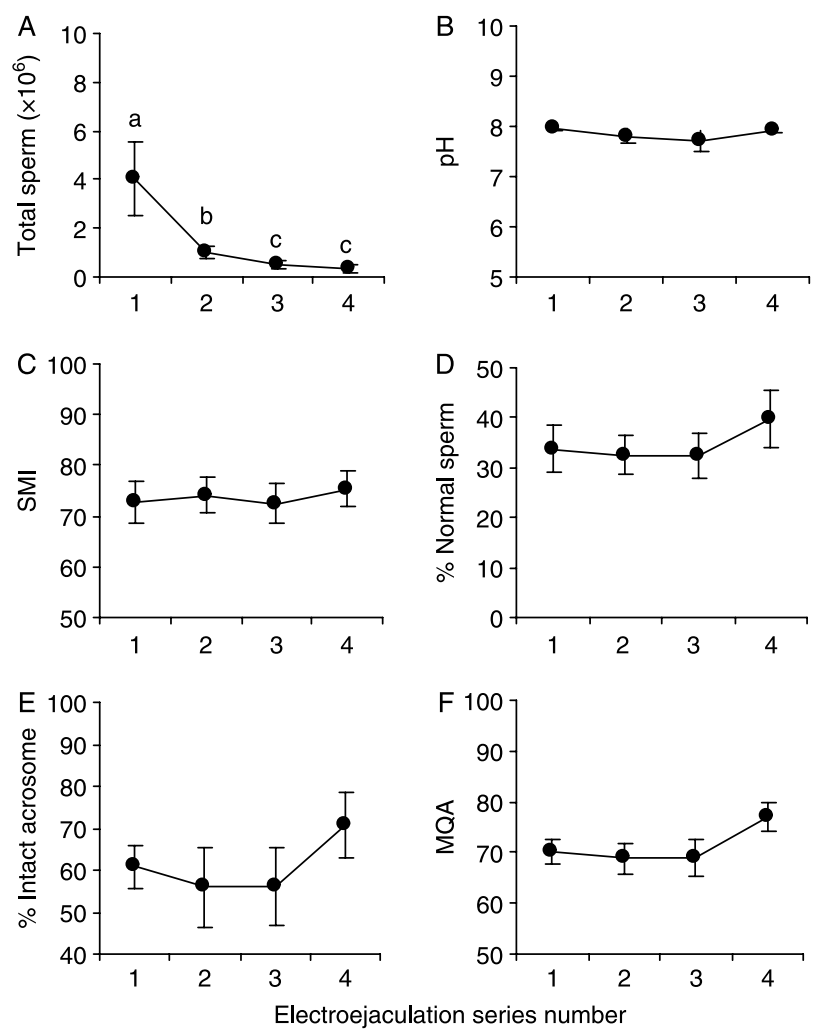

Figure 2 Sperm traits of the four electroejaculation fractions collected from captive Iberian lynx males $>3$ years old. Different letters indicate significant differences $(P<0.05)$ between series.

(Prionailurus viverrinus; Thiangtum et al. 2006) or the ocelot (Stoops et al. 2007). The Iberian lynx has a testes mass that is even smaller than that observed in smaller wild felids such as the tigrina (Morais et al. 2002) or the margay (Morais et al. 2002) with a body mass four times smaller, or the Pallas's cat (Swanson et al. 1996) with a body mass two to three times smaller. On the other hand, testicular traits are similar to those seen in the Eurasian lynx (Jewgenow et al. 2006) and bobcat (Gañán et al. 2009a). Low relative testes weight is unlikely to be related to poor nutrition or stress, since no differences were found between individuals from captive and natural populations. In addition, the fact that the testes size value obtained before and after the breeding season were similar suggests that seasonality cannot explain the small relative testes size observed. Since relative testes size is a reliable indicator of levels of sperm competition (Gomendio et al. 1998), it may reflect very low levels of female promiscuity in the field. However, the possibility that low levels of genetic variability in our lynx populations may also influence their relative testes size cannot be eliminated.

The total number of spermatozoa collected from electrostimulated adult Iberian lynx males was low compared with values recorded in other medium-sized felids, including other lynx species such as the bobcat (Gañán et al. 2009a), but were higher than those reported for the Eurasian lynx (Jewgenow et al. 2006). The present results agree with differences in testis weight between the species (reviewed in Gañán et al. 2009b). The percentage of motile spermatozoa and of spermatozoa with intact acrosomes was, in general, lower than that observed in other medium-sized felids such as ocelot, caracal, serval or fishing cat (Gañán et al. 2009b) but higher than those in Eurasian lynx (Jewgenow et al. 2006) or bobcat (Gañán et al. 2009a). The proportion of morphologically normal sperm in the ejaculate varies widely among felids (Pukazhenthi et al. 2006c), but teratospermia (more than $60 \%$ abnormal spermatozoa in the ejaculate) has a high prevalence in this family. Males of Iberian lynx produced on average a low proportion of morphologically normal sperm when compared with predominantly normospermic species like the ocelot (Baudi et al. 2008) or serval (Leptailurus serval; Pukazhenthi et al. 2002). However, values of normal sperm in Iberian lynx are similar to those recorded

Table 5 Phenotypic, testicular and sperm traits from Iberian lynx recovered post mortem.

\begin{tabular}{|c|c|c|c|c|c|}
\hline & \multicolumn{5}{|c|}{ Male } \\
\hline & FM1 & FM2 & FM3 & FM4 & Mean \pm S.E.M. \\
\hline Date of death & $14 / 03 / 05$ & 17/04/06 & 14/03/07 & 18/03/07 & \\
\hline Age (years) & 2 & 3 & 4 & 11 & $5.0 \pm 2.04$ \\
\hline Cause of death & Road kill & Road kill & Infection & Infection & \\
\hline Body weight $(\mathrm{kg})$ & 11.00 & ND & 12.35 & 8.26 & $9.2 \pm 1.61$ \\
\hline Total testes weight (g) & 5.14 & 5.92 & 6.11 & 4.70 & $5.4 \pm 0.28$ \\
\hline Relative testes weight $\left(\times 10^{-4}\right)$ & 4.67 & ND & 4.95 & 5.69 & $5.1 \pm 0.31$ \\
\hline Total number of sperm $\left(\times 10^{6}\right)$ & 7.31 & 31.15 & 0.55 & 1.96 & $10.2 \pm 1.78$ \\
\hline Motility (\%) & 0 & 45 & 0 & 50 & $47.5 \pm 2.5$ \\
\hline Quality of motility (scale, 0-5) & 0 & 2 & 0 & 2.5 & $2.2 \pm 0.25$ \\
\hline Sperm motility index (SMI) & 0 & 42.50 & 0 & 50.0 & $46.2 \pm 3.75$ \\
\hline \% Viable spermatozoa & 48 & 68.25 & 23 & ND & $46.4 \pm 13.09$ \\
\hline Morphologically normal sperm (\%) & 38 & 54 & 17 & 18 & $31.7 \pm 5.92$ \\
\hline Intact acrosome (\%) & 32 & 32 & 44 & 46 & $38.5 \pm 3.79$ \\
\hline \% Sperm without cytoplasmic droplet & 67 & 94 & 95 & 72 & $82.0 \pm 7.47$ \\
\hline
\end{tabular}

All males were from the Doñana area. Relative testes weight $=$ Total testes weight/body weight. Sperm motility index $(\mathrm{SMI})=(\% \mathrm{sperm}$ motility + $(20 \times$ quality of motility))/2. ND, not determined. 

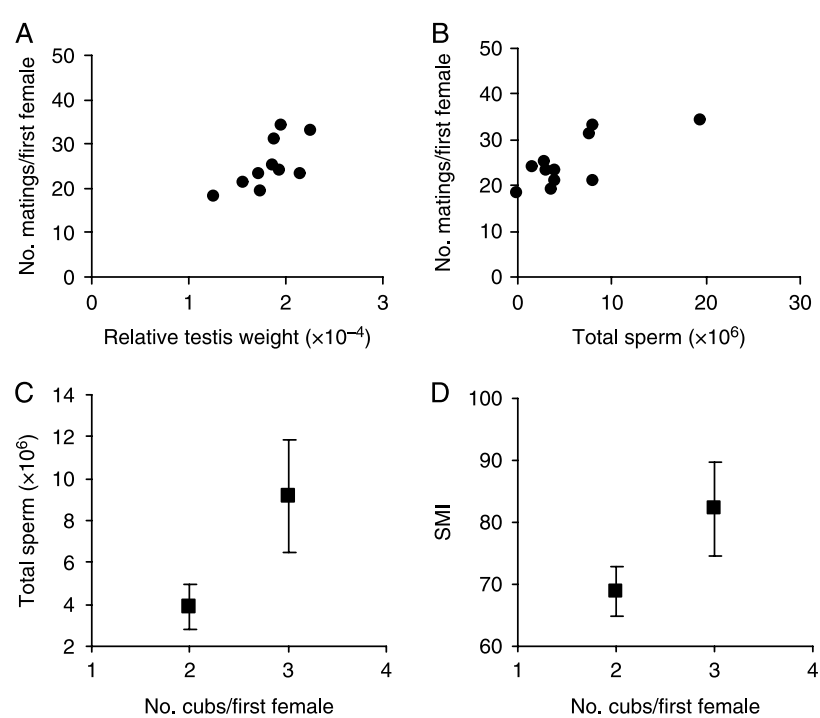

Figure 3 Relations between phenotype or semen traits of captive Iberian Iynx and male fertility $(N=12)$. (A) Relation between relative testis weight $\left(\times 10^{-4}\right)$ and number of matings with the first female when males mated with two females on separate occasions in different dates $\left(r_{\mathrm{s}}=0.75 ; P=0.01\right)$. (B) Relation between total sperm number $\left(\times 10^{6}\right)$ and number of matings with the first female $\left(r_{\mathrm{s}}=0.63 ; P=0.03\right)$. (C) Differences in total sperm number $\left(\times 10^{6}\right)$ in males siring two or three cubs after mating with the first female (Mann-Whitney $U=2.00$; $P=0.05$ ). (D) Differences in SMI in males siring two or three cubs after mating with the first female (Mann-Whitney $U=0.00 ; P=0.01$ ).

in Eurasian lynx (Howard 1993) and higher than those observed in the bobcat (Gañán et al. 2009a) or species with extremely high levels of teratospermia such as cheetah (Roth et al. 1995) and the Florida panther (Barone et al. 1994). It has been claimed that an increase in the proportion of abnormal spermatozoa is associated with an increase in sperm numbers in teratospermic cats (Neubauer et al. 2004) but we have not found a significant association between these traits in the Iberian lynx.

Iberian lynx reproductive traits, especially the low percentage of normal spermatozoa, and low circulating testosterone levels, may be related to low levels of genetic variability seen in this species, which is among the lowest documented for a felid species (Johnson et al. 2004). Previous studies have found that the high levels of teratospermia and the decrease in some male reproductive characteristics in the cheetah (Wildt et al. 1983, 1987 b, Roth et al. 1995), lion (Wildt et al. 1987a) and the Florida panther (Barone et al. 1994) are associated with low genetic variability. Future studies should address whether this is also the case in Iberian lynx and, moreover, whether the different levels of genetic variability in the two isolated populations (Johnson et al. 2004) differentially affect male phenotype and sperm quality.

Young males ( 2 years of age) had poorer semen quality than older males ( $\geq 4$ years of age), despite a lack of differences between age groups in relative testes size.
Thus, 2-year-old males were smaller in size, had lower absolute testes weight and testosterone levels, and ejaculated fewer sperm, with poorer motility and a higher proportion of abnormal sperm than older individuals. Males in the intermediate age group (3 years of age) showed semen traits with intermediate values and not significantly different from the younger or older groups. These results, thus, suggest that males that are 4 years or older could be regarded as sexually mature, whereas 2-year-old males may be regarded as juveniles. The intermediate, 3-year-old males, could be considered as subadults which have not yet reached the peak of ejaculate quality, although some males in this age group may have a semen quality similar to that of older individuals.

No differences were found between male reproductive traits before or after the breeding season. We could not examine male traits at the peak of the mating season to avoid disturbing animals either in free-ranging or captive populations. It is possible that although females have a restricted period of receptivity, males continue to produce spermatozoa until later in the year and future studies should address this possibility. Differences were detected in testes weight and relative testes weight between measures taken in vivo and those collected post mortem. The higher value identified in testes collected from dead animals and transported to the laboratory could be due to the removal of the scrotum and tunica albuginea that would normally compress the testes and, as consequence, result in smaller testes measures in live animals.

There were no major differences in sperm traits between captive and free-ranging animals; the only difference observed was a higher proportion of motile spermatozoa in captive individuals. These results are consistent with those found in the cheetah, where no differences were observed between captive and freeranging individuals (Wildt et al. 1987b, Crosier et al. 2007). This is not entirely surprising given that 1 ) most captive Iberian lynx have been introduced to captive conditions recently, 2) they receive a balanced diet, and 3) they inhabit large semi-natural enclosures. Our results contrast with evidence from the jaguar, in which free-ranging males produced a higher number of spermatozoa, and had more spermatozoa with normal morphology that males kept in zoos (Morato et al. 2001), differences that were perhaps a result of suboptimal captive conditions.

Some clear associations between phenotypic traits (relative testes weight) or sperm traits (total number of sperm, sperm motility) and males' fertility were found. The relative testes weight and number of spermatozoa showed significant relationship with number of copulations, whereas number of sperm, and sperm motility were associated with the number of cubs sired per female. These are important results that would allow us to assess in the future the reproductive potential of males 
in the captive breeding programme before the mating season. Previously, it has been difficult to establish clear links between sperm traits and male fertility in felids, possibly due to the limited number of males in captive conditions and the fact that they are scattered around many zoos. In other wild species, in which larger numbers of animals were examined, some clear associations between sperm traits and male fertility were uncovered (Malo et al. 2005, Gomendio et al. 2007).

In summary, our study revealed that in the Iberian lynx, 1) it is possible to collect semen from free-ranging males, 2) males appear to reach full sexual maturity at $\sim 4$ years of age, 3 ) there are no major differences in sperm characteristics between captive and free-ranging animals, 4) there are no differences between semen samples collected before or just after the mating season, 5 ) it is possible to recover motile epididymal spermatozoa from dead animals, and 6) several phenotypic and seminal traits correlate significantly with male sexual behaviour and fertility.

\section{Material and Methods}

\section{Animals}

Captive Iberian lynx were kept at three breeding centres: 'El Acebuche' (Doñana National Park, Huelva), 'La Olivilla' (Sierra Morena range, Jaén) and 'Zoobotanical Garden' (Jerez de la Frontera, Cádiz), all in Spain. All the males were originally trapped in the wild and, after suitable quarantine periods, were kept in captivity, with the exception of one male, Studbook (SB) number 14, who was the first male born in captivity. Males were kept under semi-natural conditions in individual enclosures with visual, auditory and olfactory contact with conspecific males and females. The enclosures had natural mixed Mediterranean vegetation. Animals were fed a balanced diet that was based on commercially-bred live rabbits, as well as rabbit carcasses, beef or quails, the latter three with vitamin supplements. Males (2-8 years old) were electroejaculated just before the breeding season in 2005, 2006 or 2007 and some were electroejaculated at the end of the season.

Free-ranging males (4-11 years old) inhabited the Doñana National Park, Huelva, Spain. Animals were electroejaculated before the breeding season in 2006. All the males were trapped in the wild and released again following adequate recovery after anaesthesia.

For both captive and free-ranging males, age at the time of electroejaculation was rounded up, for the sake of simplicity, taking into account that births occur in March-April. For example, although males born in March 2004 were 33 months old when electroejaculated in December 2006, they were regarded as 3-years-old for analyses.

All animal manipulations were performed in accordance with the Spanish Animal Protection Regulation, RD1201/2005, which conforms to European Union Regulation 2003/65, and with the necessary permits from the Andalusian government (Consejería de Medio Ambiente, Junta de Andalucía, Spain).

\section{Sperm collection and evaluation}

For semen collection, both in the field and in captivity, males were anaesthetised with tiletamine hydrochloride plus zolazepam (10 mg/kg body weight; Zoletil, Virbac, Carros, France) or with ketamine hydrochloride (5 mg/kg; Imalgene 1000, Merial, Lyon, France) plus medetomidine hydrochloride $(50 \mu \mathrm{g} / \mathrm{kg}$; Domtor, Orion Pharma, Spoo, Finland). Medetomidine effects were reversed by injection of atipamezole hydrochloride (250 $\mu \mathrm{g} / \mathrm{kg}$; Antisedan, Pfizer, Madrid, Spain).

Body weight and body and testicular dimensions, were obtained before electroejaculation. Testes weight was calculated from the volume of each testis as described by Harcourt et al. (1995).

Electroejaculation was carried out following the procedure described by Howard (1993). A lubricated rectal probe $(17.9 \mathrm{~cm}$ length and $13.45 \mathrm{~mm}$ diameter; P.T. Electronics, Boring, OR, USA) with three longitudinal electrodes $(35.7 \mathrm{~mm}$ in length) was placed in the rectum, with the electrodes at the level of the prostate and bulbourethral glands, and voltage applied. Electrical stimulations were delivered using a $60-\mathrm{Hz}$ sine-wave stimulator (P.T. Electronics). Stimuli were delivered in sets of 10 stimulations at each voltage (range 2-5 V) with the total sequence divided into four series (first series: 2, 3, $4 \mathrm{~V}$; second series: 3, 4, $5 \mathrm{~V}$; third series: 4, $5 \mathrm{~V}$; fourth series: $4,5 \mathrm{~V})$. Semen was collected in prewarmed sterile $25 \mathrm{ml}$ polypropylene cups (LabCenter, Madrid, Spain).

Semen obtained in each series was evaluated immediately for volume (using a micropipette) and $\mathrm{pH}$ (using test strips; Medi-Test Combi 9, Machereg-Nagel, Düren, Germany). A semen aliquant $(5 \mu \mathrm{l})$ was examined under phase contrast optics to assess the percentage of motile spermatozoa and the quality of movement (using a scale of $0-5$, where 0 is no movement and 5 represents rapid, linear forward progression; Howard et al. 1986). Motility values were used to calculate a SMI using the formula $(\%$ motile sperm $+($ quality $\times 20)) / 2$ (Howard 1992).

From each electroejaculation series semen aliquants were fixed with $1 \%$ glutaraldehyde solution in $0.165 \mathrm{M}$ cacodylate buffer $(\mathrm{pH} 7.3)$ and $4 \%$ paraformaldehyde in $110 \mathrm{mM}$ $\mathrm{Na}_{2} \mathrm{HPO}_{4}$ plus $2.5 \mathrm{mM} \mathrm{NaH} \mathrm{PO}_{4}$ buffer solution $(\mathrm{pH} 7.4$; Gañán et al. 2009a, 2009b). Fixed samples were used to estimate sperm concentration and to assess sperm morphology and acrosomal integrity respectively. Concentration was estimated using a Neubauer counting chamber. For sperm morphology and acrosomal integrity evaluation, we prepared smears that were stained with Coomassie brilliant blue (Larson \& Miller 1999). To assess morphology, 100 spermatozoa were examined and categorized as in previous studies (Gañán et al. 2009a, 2009b). Acrosomal integrity was assessed in another set of 100 spermatozoa and classified as in other felid species (Pukazhenthi et al. 2006b, Gañan et al. 2009a, 2009b). Motility values and the proportion of spermatozoa with intact acrosomes were used to calculate a MQA thus: (\% motile sperm $+($ quality $\times 20)+\%$ intact acrosomes $) / 3$.

The remaining semen sample was diluted with an equal volume of Hepes-containing Ham's F-10 medium (Irvine Scientific, Izasa, Barcelona, Spain) with 5\% heat-inactivated foetal bovine serum (Gibco Invitrogen) and maintained at room temperature until the end of the electroejaculation protocol. 
Then, semen was processed for cryopreservation as described (Gañán et al. 2009b) and stored in a genome resource bank (Roldan et al. 2006b, 2009).

\section{Collection of epididymal spermatozoa}

Spermatozoa were collected from males that died in the field in the Doñana area. Testes and epididymides were removed as soon as possible, placed in plastic bags, transported to the laboratory at $5{ }^{\circ} \mathrm{C}$ inside a styrofoam container and processed within hours of the animals' death. The testes were dissected and measured, the epididymis separated and cut transversely with a scalpel blade, and placed in $0.4 \mathrm{ml}$ of Tes-Tris buffer (Gañán et al. 2009b) in a Petri dish $(35 \times 10 \mathrm{~mm}$ Falcon, Becton Dickinson, Le Pont De Claix, France) for $10 \mathrm{~min}$. The volume of sperm suspension was measured with a micropipette and transferred to a $1.5 \mathrm{ml}$ sterile microtube. Sperm motility was assessed and two sperm aliquots were taken, one to assess concentration and the other to assess sperm morphology and acrosome integrity; fixation, staining and sperm assessments were carried out as described above for ejaculated spermatozoa.

\section{Testosterone and cortisol quantification}

Blood samples were collected, centrifuged for serum collection and samples stored at $-80^{\circ} \mathrm{C}$. Serum testosterone and cortisol were analyzed in a commercial laboratory using a solid-phase, competitive chemiluminescent enzyme immunoassay (Immulite 1000, Siemens Healthcare Diagnostics, Deerfield, IL, USA).

\section{Statistical analyses}

Data were analyzed using SPSS, version 11.5 (SPSS Inc., Chicago, IL, USA). Results are presented as mean \pm s.E.M. A value of $P<0.05$ was regarded as statistically significant. To compare sperm variables between all three age groups a Kruskal-Wallis one-way ANOVA by ranks was carried out; comparisons between age group pairs were done using a Mann-Whitney $U$ test. Ejaculates from free-living or captive animals were compared using a Mann-Whitney $U$ test. The comparison of ejaculates collected before (winter) or after (spring) the breeding season was done using a Wilcoxon test for paired samples. Analyses of ejaculate fractions in captive and free-ranging males were carried out using a non-parametric Friedman test to $k$-related samples. When results were significant, a non-parametric Wilcoxon signed-rank test for paired samples was used.

Relationships between testicular, hormonal and ejaculate traits and between these and reproductive outcome in captivity were analyzed by non-parametric Spearman rank correlations. Differences in total number of spermatozoa and SMI between males that sired two or three cubs per female were analyzed by using the Mann-Whitney $U$ test.

\section{Declaration of interest}

The authors declare that there is no conflict of interest that could be perceived as prejudicing the impartiality of the research reported.

\section{Funding}

Natalia Gañán received postgraduate support from the Spanish Research Council (CSIC-I3P programme) and the BBVA Foundation. Adrián Sestelo received a scholarship funded by the BBVA Foundation. E R S Roldan is the recipient of a Royal Society Wolfson Research Merit Award. This work was carried out with grants from the Spanish Ministry of the Environment (DG Biodiversity to E R S R, M G, and National Parks to F P), the Spanish Research Council (to E R S R and M G), the Ministry of Education and Science (to F P) and the BBVA Foundation (to M G). Novauto (Ford España) generously donated a vehicle for field work.

\section{Acknowledgements}

We thank David Wildt, JoGayle Howard, Rachel M Santymire and Katharine Pelican for initial support in setting up techniques of semen collection and evaluation. The following people from the 'El Acebuche' and 'La Olivilla' centres and Zoobotánico Jerez are gratefully acknowledged for help with various tasks: Juana Bergara, Luis Díez Klink, José Manuel Rodríguez, David Rodríguez, Antonio Rivas, Tasio Vázquez, Antonio Juan Pardo, Javi López, Eva Vázquez, José María Aguilar, Miguel Ángel Quevedo, Luis Flores, Mariano Cuadrado, Claribel León, Olga Jiménez, Vanessa Lobato and Antonio Herrera. Antonio Rivas is thanked for the photograph in Fig. 1A. Cristina Martínez and Guillermo López are thanked for their support with animal anaesthesia. Sandra Bañuls helped with anaesthesia and monitoring. Juan Carlos Revilla, Leo Fernández and Marcos López are acknowledged for efforts in trapping and releasing free-ranging lynx of the Doñana population. Ana del Olmo and Lucía Arregui collaborated with field work in 2005. Begoña de la Cruz is thanked for her help with lab work in 2007. Borja Heredia and Miguel Aymerich (Ministerio de Medio Ambiente, Spain) and Miguel Angel Simón (Junta de Andalucia, Spain), are thanked for their support of this study.

\section{References}

Alda F, Inogés J, Alcaraz L, Oria J, Aranda A \& Doadrio I 2008 Looking for the Iberian lynx in central Spain: a needle in a haystack? Animal Conservation 11 297-305.

Barone MA, Roelke ME, Howard JG, Brown JL, Anderson AE \& Wildt DE 1994 Reproductive characteristics of male Florida panthers: comparative studies from Florida, Texas, Colorado, Latin America and North American zoos. Journal of Mammalogy 75 150-162.

Baudi DLK, Jewgenow K, Pukazhenthi B, Spercoski KM, Santos AS, Reghelin ALS, Candido MV, Javorouski ML, Müller G \& Morais RN 2008 Influence of cooling rate on the ability of frozen-thawed sperm to bind to heterologous zona pellucida, as assessed by competitive in vitro binding assay in the ocelot (Leopardus pardalis) and tigrina (Leopardus tigrinus). Theriogenology 69 204-211.

Bernard RTF \& Stuart CT 1987 Reproduction of the caracal Felis caracal from the Cape Province of South Africa. South African Journal of Zoology 22 177-182.

Blanco JC 1998 Mamíferos de España, Barcelona: Editorial Planeta.

Crosier AE, Marker L, Howard JG, Pukazhenthi BS, Helghali JH \& Wildt DE 2007 Ejaculate traits in the Namibian cheetah (Acinonyx jubatus): influence of age, season and captivity. Reproduction, Fertility, and Development 19 370-382. 
Delibes M 1979 Le Lynx dans la péninsule iberique: repartition et regresion. Bulletin Mensuel de I'Office Nationale de la Chasse, Numéro Spéciale Scientifique et Technique Le Lynx, pp 41-55.

Fernández N, Palomares F \& Delibes M 2002 The use of breeding dens and the kitten development in the Iberian lynx (Lynx pardinus). Journal of Zoology 258 1-5.

França LR \& Godinho CL 2003 Testis morphometry, seminiferous epithelium cycle length, and daily sperm production in domestic cat (Felis catus). Biology of Reproduction 68 1554-1561.

Gañán N, González R, Sestelo A, Garde JJ, Sánchez I, Aguilar JM, Gomendio M \& Roldan ERS 2009a Male reproductive traits, semen cryopreservation and heterologous in vitro fertilization in the bobcat (Lynx rufus). Theriogenology 72 341-352.

Gañán N, González R, Garde JJ, Martínez F, Vargas A, Gomendio M \& Roldan ERS $2009 \mathrm{~b}$ Assessment of semen quality, sperm cryopreservation and heterologous IVF in the critically endangered Iberian lynx (Lynx pardinus). Reproduction, Fertility, and Development 21 848-859.

Godoy JA, Casas M \& Fernández J 2009 Genetic issues in the implementation of the Iberian lynx ex situ conservation program. In Iberian Lynx Ex-Situ Conservation: An Interdisciplinary Approach, pp 86-99. Eds A Vargas, C Breitenmoser \& U Breitenmoser. Madrid: Fundación Biodiversidad.

Gomendio M, Harcourt AH \& Roldan ERS 1998 Sperm competition in mammals. In Sperm Competition and Sexual Selection, pp 667-751. Eds TR Birkhead \& AP Moller. London: Academic Press.

Gomendio M, Malo AF, Garde J \& Roldan ERS 2007 Sperm traits and male fertility in natural populations. Reproduction 134 19-29.

Guzmán López-Ocón JN, García González FJ, Garrote Alonso G, Pérez de Ayala Balzola R \& Iglesias Llamas C 2002 El Lince ibérico (Lynx pardinus) en España y Portugal. Censo-diagnóstico de sus poblaciones. Madrid: Ministerio de Medio Ambiente.

Haas van Dorsser FJ \& Strick JA 2005 Semen characteristics and sperm morphology in the Arabian leopard (Panthera pardus nimr) and how these vary with age and season. Reproduction, Fertility, and Development 17 675-682.

Harcourt AH, Purvis A \& Liles L 1995 Sperm competition: mating system, not breeding season, affects testes size of primates. Functional Ecology 9 $468-476$.

Howard JG 1992 Feline semen analysis and artificial insemination. In Kirk's Current Veterinary Therapy XI Small Animal Practice, pp 929-938. Eds JD Kirk \& RW Bonagura. Philadelphia, PA: WB Saunders.

Howard JG 1993 Semen collection and analysis in carnivores. In Zoo and Wildlife Medicine, 3 edn, pp 390-398. Ed. ME Fowler. Philadelphia, PA: WB Saunders.

Howard JG, Bush DVM \& Wilt DE 1986 Semen collection, analysis and cryopreservation in nondomestic mammals. In Current Therapy in Theriogenology, pp 1047-1053. Ed. DA Morrow. Philadelphia, PA: WB Saunders.

IUCN 2009 IUCN Red List of Threatened Species. Version 2009.1. <www. iucnredlist.org $>$. Downloaded on 12 June 2009.

Jewgenow K, Goeritz F, Neubauer K, Fickel J \& Naidenko SV 2006 Characterization of reproductive activity in captive male Eurasian lynx (Lynx lynx). European Journal of Wildlife Research 52 34-38.

Johnson WE, Godoy JA, Palomares F, Fernández M, Revilla E \& O’Brien SJ 2004 Phylogenetic and phylogeographic analysis of Iberian lynx populations. Journal of Heredity 95 19-28.

Johnston LA, Armstrong DL \& Brown JL 1994 Seasonal effects on seminal and endocrine traits in the captive snow leopard (Panthera uncia). Journal of Reproduction and Fertility 102 229-236.

Kenagy GJ \& Trombulak SC 1986 Size and function of mammalian testes in relation to body size. Journal of Mammalogy 67 1-22.

Larson JL \& Miller DJ 1999 Simple histochemical stain for acrosomes on sperm from several species. Molecular Reproduction and Development 52 445-449.

Lasley BL, Loskutoff NM \& Anderson GB 1994 The limitation of conventional breeding programs and the need and promise of assisted reproduction in nondomestic species. Theriogenology 41 119-132.

Luvoni GC 2006 Gamete cryopreservation in the domestic cat. Theriogenology 66 101-111.

Malo AF, Garde JJ, Soler AJ, García AJ, Gomendio M \& Roldan ERS 2005 Male fertility in natural populations of red deer is determined by sperm velocity and the proportion of normal spermatozoa. Biology of Reproduction 72 822-829.
Morais RN, Mucciolo RG, Gomes MLF, Lacerta O, Moraes W, Moreira N, Gram LH, Swanson WF \& Brown JL 2002 Seasonal analysis of semen characteristics, serum testosterone and fecal androgens in the ocelot (Leopardus pardalis), margay (L. wiedii) and tigrina (L. tigrinus). Theriogenology 57 2027-2041.

Morato RG, Conforti VA, Azevedo FC, Jacomo ATA, Silveira L, Sana D, Nunes ALV, Gimaraes MABV \& Barnabe RC 2001 Comparative analyses of semen and endocrine characteristics of free-living versus captive jaguars (Panthera onca). Reproduction 122 745-751.

Morato RG, Verrreschi ITN, Guimaraes MABV, Cassaro K, Pessuti C \& Barnabe RC 2004 Seasonal variation in the endocrine-testicular function of captive jaguars (Panthera onca). Theriogenology 61 1273-1281.

Neubauer K, Jewgenow K, Blottner S, Wildt DE \& Pukazhenthi B 2004 Quantity rather than quality in teratospermic males: a histomorphometric and flow cytometric evaluation of spermatogenesis in the domestic cat (Felis catus). Biology of Reproduction 71 1517-1524.

Nowell K \& Jackson P 1996 Wild Cats: Status Survey and Conservation Action Plan. Gland, Switzerland: UICN/SSC Cat Specialist Group.

Palomares F, Delibes M, Revilla M, Calzada J \& Fedriani JM 2001 Spatial ecology of Iberian lynx and abundance of European rabbits in southwestern Spain. Wildlife Monographs 148 1-35.

Palomares F, Revilla E, Fernández N \& Delibes M 2005 Reproduction and pre-dispersal survival of Iberian lynx in a subpopulation of the Doñana National Park. Biological Conservation 122 53-59.

Pope CE, Gomez MC \& Dresser BL 2006 In vitro embryo production and embryo transfer in domestic and non-domestic cats. Theriogenology 66 1518-1524.

Pukazhenthi BS \& Wildt DE 2004 Which reproductive technologies are most relevant to studying, managing and conserving wildlife? Reproduction, Fertility, and Development 16 33-46.

Pukazhenthi B, Spindler R, Wildt DE, Bush LM \& Howard JG 2002 Osmotic properties of spermatozoa from felids producing different proportions of pleiomorphisms: influence of adding and removing cryoprotectant. Cryobiology 44 288-300.

Pukazhenthi B, Comizzoli P, Travis AJ \& Wildt DE 2006a Applications of emerging technologies to the study and conservation of threatened and endangered species. Reproduction, Fertility, and Development 18 7-90.

Pukazhenthi B, Laroe D, Crosier A, Bush LM, Spindler R, Pelican KM, Bush M, Howard JG \& Wildt DE $2006 b$ Challenges in cryopreservation of clouded leopard (Neofelis nebulosa) spermatozoa. Theriogenology $\mathbf{6 6}$ 1790-1796.

Pukazhenthi B, Neubauer K, Jewgenow K, Howard JG \& Wildt DE 2006 C The impact and potential etiology of teratospermia in the domestic cat and its wild relatives. Theriogenology 66 112-121.

Rodríguez A 2007 Lynx pardinus (Temminck, 1827). In Atlas y Libro Rojo de los Mamíferos de España, pp 342-344. Eds LJ Palomo, J Gisbert \& JC Blanco. Madrid: Dirección General para la Biodiversidad-SECEMSECEMU.

Rodríguez A \& Delibes M 2003 Population fragmentation and extinction in the Iberian lynx. Biological Conservation 109 321-331.

Rodriguez A \& Delibes M 2004 Patterns and causes of non-natural mortality in the Iberian lynx during a 40-year period of range contraction. Biological Conservation 118 151-161.

Roldan ERS \& Garde JJ 2004 Biotecnología de la reproducción y conservación de especies en peligro de extinción. In Los Retos Medioambientales del Siglo XXI. La Conservación de la Biodiversidad en España, pp 283-303. Ed. M Gomendio. Madrid: Fundación BBVA-CSIC.

Roldan ERS \& Gomendio M 2009 Sperm and conservation. In Sperm Biology, pp 539-564. Eds TR Birkhead, D Hosken \& S Pitnick. London: Academic Press.

Roldan ERS, Gomendio M, Garde J, Espeso G, Ledda S, Berlinguer F, del Olmo A, Soler AJ, Arregui L, Crespo C et al. 2006a Inbreeding and reproduction in endangered ungulates: preservation of genetic variation through the organisation of genetic resource banks. Reproduction in Domestic Animals 41 82-92.

Roldan ERS, Gañán N, Crespo C, González R, Arregui L, del Olmo A, Garde JJ \& Gomendio M 2006b A genetic resource bank and assisted reproductive techniques for the Iberian lynx. In Iberian Lynx Ex-Situ Conservation, pp 101-105. Ed. A Vargas. Madrid: Fundación Biodiversidad and Ministerio de Medio Ambiente. 
Roldan ERS, Gomendio M, Garde JJ, Gañán N, González R, Crespo C \& Arregui L 2009 A genetic resource bank for the critically endangered Iberian Iynx. In Iberian Lynx Ex-Situ Conservation: An Interdisciplinary Approach, pp 304-314. Eds A Vargas, C Breitenmoser \& U Breitenmoser. Madrid: Fundación Biodiversidad.

Roth TL, Swanson WF, Blumer E \& Wildt DE 1995 Enhancing zona penetration by spermatozoa from a teratospermic species, the cheetah (Acinonyx jubatus). Journal of Experimental Biology 271 323-330.

Stoops MA, Bond JB, Bateman HL, Campbell MK, Levels GP, Bowsher TR, Ferrell ST \& Swanson WF 2007 Comparison of different sperm cryopreservation procedures on post-thaw quality and heterologous in vitro fertilisation success in the ocelot (Leopardus pardalis). Reproduction, Fertility, and Development 19 685-694.

Swanson WF 2006 Application of assisted reproduction for population management in felids: the potential and reality for conservation of small cats. Theriogenology 66 49-58.

Swanson WF, Brown JL \& Wildt DE 1996 Influence of seasonality on reproductive traits of the male Pallas' cat (Felis manul) and implications for captive management. Journal of Zoo and Wildlife Medicine 27 234-240.

Swanson WF, Stoops MA, Magarey GM \& Herrick JR 2007 Sperm cryopreservation in endangered felids: developing linkage of in situex situ populations. In Spermatology, pp 417-432. Eds ERS Roldan \& M Gomendio. Nottingham: Nottingham University Press.

Tebet JM, Martins MIM, Chirinea VH, Souza FF, Campagnol D \& Lopes MD 2006 Cryopreservation effects on domestic cat epididymal versus electroejaculated spermatozoa. Theriogenology 66 1629-1632.

Thiangtum K, Swanson W, Howard JG, Tunwattana W, Tongthainam D, Wichasilpa W, Patumrattanathan P \& Pinyopoommintr T 2006 Assessment of basic seminal characteristics, sperm cryopreservation and heterologous in vitro fertilisation in the fishing cat (Prionailurus viverrinus). Reproduction, Fertility, and Development 18 373-382.

Valverde JA 1963 Información sobre el Lince Español, Madrid: Servicio Nacional de Pesca Fluvial y Caza.

Vargas A, Sanchez I, Godoy J, Roldan E, Martínez F, Simón MA (Eds) 2007 Revised Action Plan for Captive Breeding of Iberian Lynx, 4 edn. Madrid: Ministerio de Medio Ambiente.

Vargas A, Sánchez I, Martínez F, Rivas A, Godoy JA, Roldan E, Simón MA, Serra R, Pérez MJ, Enseñat C et al. 2008 The Iberian lynx Lynx pardinus conservation breeding program. International Zoo Yearbook $\mathbf{4 2}$ 190-198.
Vargas A, Sánchez I, Martínez F, Rivas A, Godoy JA, Roldan E, Simón MA, Serra R, Prez MJ, Sliwa A et al. 2009 Interdisciplinary methods in the Iberian lynx (Lynx pardinus) conservation breeding programme. In Iberian Lynx Ex-Situ Conservation: An Interdisciplinary Approach, pp 56-71. Eds A Vargas, C Breitenmoser \& U Breitenmoser. Madrid: Fundación Biodiversidad.

Wildt DE 1990 Potencial applications of IVF technology for species conservation. In Fertilization in Mammals, pp 349-364. Eds BD Bavister, J Cummins \& ERS Roldan. Norwell, MA: Serono Symposia.

Wildt DE 1994 Endangered species spermatozoa: diversity, research, and conservation. In Function of Somatic Cells in Testes, pp 1-24. Ed. A Bartke. New York: Springer-Verlag.

Wildt DE, Bush M, Howard JG, O'Brien SJ, Meltzer D, Van Dyk A, Ebedes H \& Brand DJ 1983 Unique seminal quality in the South African cheetah and a comparative evaluation in the domestic cat. Biology of Reproduction 29 1019-1025.

Wildt DE, Howard JG, Hall LL \& Bush M 1986 Reproductive physiology of the clouded leopard: I. Electroejaculates contain high proportion of pleimorphic spermatozoa throughout the year. Biology of Reproduction 34 937-947.

Wildt DE, Bush M, Goodrowe KL, Packer C, Pusey AE, Brown JL, Joslin P \& O'Brien SJ 1987 a Reproductive and genetic consequences of founding isolated lion populations. Nature 329 328-331.

Wildt DE, O'Brien SJ, Howard JG, Caro TM, Roelke ME, Brown JL \& Bush M 1987b Similarity in ejaculate-endocrine characteristics in captive versus free-ranging cheetahs of two subspecies. Biology of Reproduction 36 351-360.

Wildt DE, Brown JL, Bush M, Barone MA, Cooper KA, Grisham J \& Howard JG 1993 Reproductive status of cheetahs (Acinonyx jubatus) in North American zoos: the benefits of physiological surveys for strategic planning. Zoo Biology 12 45-80.

Wildt DE, Pukazhenthi B, Brown J, Monfort S, Howard JG \& Roth T 1995 Spermatology for understanding, managing and conserving rare species. Reproduction, Fertility, and Development 7 811-824.

Received 24 June 2009

First decision 28 July 2009

Accepted 4 September 2009 